\title{
Influence of Social Constraints, Mobility Incentives, and Restrictions on Commuters' Behavioral Intentions and Moral Obligation towards the Metro-Bus Service in Lahore
}

\author{
Muhammad Ashraf Javid ${ }^{1}\left(\mathbb{D}\right.$, Nazam Ali $^{2} \mathbb{D}$, Tiziana Campisi ${ }^{3, * \mathbb{D}}$, Giovanni Tesoriere $^{3} \mathbb{D}$ \\ and Krisada Chaiyasarn ${ }^{4}$ (D)
}

1 Department of Civil Engineering, NFC Institute of Engineering and Fertiliser Research, Faisalabad, Punjab 38090, Pakistan; ma.javid@iefr.edu.pk

2 Department of Civil Engineering, University of Management and Technology, Lahore 54770, Pakistan; nazam.ali@umt.edu.pk

3 Faculty of Engineering and Architecture, Kore University of Enna, Cittadella Universitaria, 94100 Enna, Italy; giovanni.tesoriere@unikore.it

4 Thammasat Research Unit in Infrastructure Inspection and Monitoring, Repair and Strengthening (IIMRS), Thammasat School of Engineering, Faculty of Engineering, Thammasat University Rangsit, Klong Luang 12121, Thailand; ckrisada@engr.tu.ac.th

* Correspondence: tiziana.campisi@unikore.it

\section{check for}

updates

Citation: Javid, M.A.; Ali, N.;

Campisi, T.; Tesoriere, G.; Chaiyasarn,

K. Influence of Social Constraints,

Mobility Incentives, and Restrictions on Commuters' Behavioral Intentions and Moral Obligation towards the

Metro-Bus Service in Lahore.

Sustainability 2022, 14, 2654. https:// doi.org/10.3390/su14052654

Academic Editors: Renata

Żochowska and Marianna Jacyna

Received: 29 January 2022

Accepted: 18 February 2022

Published: 24 February 2022

Publisher's Note: MDPI stays neutral with regard to jurisdictional claims in published maps and institutional affiliations.

Copyright: (c) 2022 by the authors. Licensee MDPI, Basel, Switzerland. This article is an open access article distributed under the terms and conditions of the Creative Commons Attribution (CC BY) license (https:// creativecommons.org/licenses/by/ $4.0 /)$.

\begin{abstract}
This paper aims to identify commuters' perceptions towards the metro-bus service system considering various social constraints, mobility incentives and restrictions, and personal norms. A questionnaire survey was designed, which consisted of the personal information of respondents, travel properties, and preferences with the metro-bus system. This survey was conducted in Lahore city, and a total of 333 samples were obtained. The findings of the Structural Equation Modeling (SEM) revealed that the social constraints in traveling, public transport incentives, and specific parking restrictions have a significant influence on commuters' moral obligations to reduce traffic congestion, mitigate environmental menaces, and protect natural resources. The ANOVA and SEM analysis showed that significant differences exist among low-, middle-, and high-income commuters in terms of their behavioral intentions towards the metro-bus service. These findings implicate that specific incentives on the use of public transport modes and parking restrictions are useful in changing the behavioral intentions of travelers towards transit modes such as the metro-bus service.
\end{abstract}

Keywords: public transport; behavioral intentions; metro-bus; attitudes; mobility restrictions

\section{Introduction}

The unprecedented increase in the urban population and the vehicle ownership and its excessive dependence have increased the travel demand on the urban road network. The high trend of automobile dependency tends to increase traffic congestion and related social and external costs. The public transport system is one of the essential entities of the urban transport system, as the movement of people is mainly determined based on the quality of the transport system. It is stated that choices on public transport systems determine the city's future regarding residence and workplace choice [1]. It is also believed that individuals' attitudes and intentions towards public transport policies are controlled and influenced by the socio-demographics of the commuters, and it is a learning process that evolves over time [2-4]. Many research studies have revealed that the behavioral intentions to use public transport are mainly influenced by the perceived quality of the transport service, environmental concerns, problem awareness, and sense of responsibility among the commuters about negative outcomes of personalized vehicle use behavior pertinent to the environment and socio-economic factors [5-9]. 
Different transit systems possess unique characteristics of service quality, e.g., the bus rapid transit system differs from the conventional bus service in several ways, such as the fact that it has an exclusive right of way and more frequent, comfortable, and reliable service. It is reported that bus rapid transit systems or bus-bays have significant potential to enhance the ridership of public transport. These bus lanes encourage mode switching from private vehicles to transit modes, resulting in reduced travel time and urban traffic congestion [10]. Researchers believe that people-based measures are more effective in assessing the impacts of public transport in reducing traffic congestion [11]. The commuter's behavioral intentions towards transit services are mostly affected by their perceptions about service quality and satisfaction with the service [12]. Travel demand management (TDM) policies are required to integrate and encourage more sustainable transport systems [13]. Mobility incentives, such as low fare level, reliable service, comfortable ride, and disincentives for car use, such as parking restrictions and other taxes, are important TDM policies to promote sustainable travel behavior among commuters [5,14-16]. The situational, psychological, personal, and social constraints also have a significant influence on travelers' mode choice behavior [17-19]. It is pertinent to mention that some of the additional factors also influence the transit ridership of public transport, and transit ridership can be predicted using different modeling techniques, such as Artificial Neural Networking (ANN) [20], data from smart cards using temporal motifs [21], and Modular Convolutional Neural Networks (MCNNs) [22].

There is a range of factors influencing the public transport intentions of commuters. The intentions and attitudes are especially governed by the local mobility restrictions and incentive schemes and the service quality of competitive travel alternatives $[5,23]$. To encourage switching from car to mass-transit modes such as the metro-bus service, it is required to identify suitable transport policies considering the local economic, social, cultural, and transport infrastructure service conditions. It is also required to assess the potential of suitable parking-management measures, such as parking fees and limited parking spaces, to improve a model shift of transit modes. The findings of such perceptionbased research studies can help concerned stakeholders and authorities in considering the necessary intervention for the improvements in the public transport system. Therefore, this study aims to explore commuters' behavioral intentions and moral obligations towards the metro-bus service in Lahore. Various social and personal factors, the restrictions of mobility options, and the incentive systems about public transport are considered in this assessment. The travelers' moral obligation to use metro-bus for a reduction in environmental pollution and preservation of natural resources are also part of this assessment. The data were collected through the administration of a questionnaire survey that was conducted in Lahore city. The collected data were analyzed using ANOVA testing, and a Structural Equation Modeling approach was adopted for the investigation of correlations between different latent variables. Comparison analysis between low-income, middle-income, and high-income groups for behavioral intentions is also presented. The rest of the research paper is written in the following manner. Section 2 presents the relevant literature, and study area characteristics are discussed in Section 3. In Section 4, the research methods are elaborated. The results of the questionnaire survey and the findings are discussed in Section 5. Finally, the main findings and conclusions of this research study are summarized.

\section{Literature Review}

The bus rapid transit (BRT) or metro-bus system (MBS) differs from other public transport modes, such as conventional bus service, light-rail transit (LRT), and streetcars, in infrastructure requirements and operational characteristics. Metro-bus systems usually have an exclusive right of way or dedicated lanes of the highway for bus operation, and the construction of infrastructure for a BRT or metro-bus system is less expensive as compared to the rail infrastructure both in terms of time and money [24,25]. It provides a fast, reliable, secure, frequent, safe, convenient, comfortable, and affordable service to users [26,27]. Metro-bus system provides better service than conventional bus service which is usually 
shared right of way with other traffic and takes more travel time. The metro-bus systems are usually preferred in developing regions due to their low construction costs and they do not depend upon the electric power supply, which is one of the important concerns for countries with issue of power shortage [28]. LRT is an environmental friendly public transport choice and it can offer high capacity at lower operating costs [29]. In comparison, LRT is environmental friendly to BRT or metro-bus system, whereas BRT is a cost-effective solution to the public transport needs [29]. The choice between different transit modes such as BRT or LRT in a developing country also depends on people's preferences and behavioral intentions, city size, cost effectiveness, availability of land or right of way, environmental concerns and social and political acceptance [30]. The prospects of a particular public transport mode are needed to be evaluated in terms of user's acceptance and behavioral intentions for achieving required objectives.

The improvements in public transport modes play an imperative role in the travel decision making of the local people. The transit service quality needs to meet the demand of potential travelers. A study revealed that traveler's age, gender, and marital status have an indirect influence on commuter's mode choice and the costs incurred due to number of transfer points and distance to the nearest transit stations are significant factors that hinder commuters from selecting the public transit system [31]. Fare reduction and other associated incentives are effective in promoting the use of public transportation [32]. The driving age, car ownership, and income have the greatest impact on Pro-environment Travel (PET) behavior. Additionally, perceived service quality of transit and Socio-economic Characteristics (SEDs) of commuters play a significant role in the traveler's decisions and are strongly associated with PET behavior [33]. The female riders and those who belong to low-household-income and live 5-10 km from the university have more favorable attitudes towards public transport [34].

It is revealed that the comfort and security latent variables have a direct and significant effect on the quality of public transit system [35]. The comfort experience of travelers plays an essential role in determining the service satisfaction of the commuters, and women are believed to be more sensitive as compared to males in their attribute. Crowding in the public transport system has a direct and negative influence on how commuters rate their travel experiences [36]. However, a study in Calgary showed that the people value 'reliability and convenience' over ride-comfort in public transport which implicates that improvement in the train service connectivity, reducing transfer points, and providing exclusive rights-of-way for public transport services would increase transit ridership [37]. It is also believed that an increase in the car travel cost and improvement in the service quality of public transport are both helpful in switching car users to public transport [38]. The comfort, travel cost, and reliability play a significant role in the willingness of commuters to travel by public transport [38]. Researchers believed that the perceived value of a trip using a the transit service is one of the most important factors of behavioral intentions [39]. Other studies have shown that access to important destinations by transit modes is also significant for the preferences of commuters with the transit system [3,40,41]. The land-use patterns and travel speeds are significant predictors of the travel demand and high use of the public transport systems which results in the reduction of energy use and emissions [42].

It is found that the passengers of a bus-way are influenced by their preferential (riding experience), moral (pro-environmental concerns), and travel constraints considerations [13]. The traveler's problem experience and public perceived perceptions about service quality put a strong impact on peoples' behavioral intentions towards transit modes [43]. It has been reported that the Descriptive Norm $(\mathrm{DN})$, the relationships between the intentions and the Perceived Behavioral Control (PBC) significantly determine the student's experiences about bus ridership [44]. Researchers have argued that to make a model shift to public transport, transport policies should focus on individual's environmental-related beliefs, norms, and situational constraints [45]. It is believed that mobility restrictions on the use of a private car are mandatory to increase the travel demand of public transport modes [46]. 
Parking management measures such as limited and paid parking are always effective in making behavioral changes among travelers especially in urban areas $[14,47,48]$.

The behavioral intentions to use BRT service are determined by the perceived social influence or subjective norms and private car users have less intentions to use BRT [49,50]. Other researchers have argued that attitudes toward public transport are dominant in determining behavioral intentions in comparison to their social influence or subjective norms and perceived behavioral control [51]. The travel cost also plays significant role in the mode choice behaviors. A study using a stated choice experiment showed that the travel time, fare and comfort are prominent factors in determining BRT choice in Dar es Salaam, Tanzania [52]. The service quality attributes, individual's attitudes and environmental impacts are found to have positive influence on the behavioral intentions of commuters to use the public transport modes [53]. The social, religious and cultural context of the country tend to influence in shaping the female mobility choices, and age, household income, and marital status significantly decrease the female mobility choices in the developing regions [54]. Researchers have identified the major challenges of the women mobility with BRT service in Lahore which includes harassment at stations and in buses, the availability of limited facilities, especially for the elderly people, the limited dedicated space for the females in the buses and the inconvenient behavior of passengers at the ticketing booths during rush hours [55]. It has been found that commuter's perceptions about BRT service quality vary across different demographics aspects, such as gender, travel time, profession type, education, and purpose of trip. It is also reported that commuter's perceptions differ across different regions [56].

The above-mentioned literature reveals that several factors including attributes of the service quality, situational constraints, mobility restrictions, incentives, and personal norms influence the individual's behavioral intentions to use the public transport modes including BRT or metro-bus services. However, the significant influencing factors may have different policy implications concerning to a specific region because the social, cultural values, local regulations, and the public transport characteristics vary among different regions. The transportation improvement policies derived based on the findings of a particular case study may not produce the desired results for another region as each region or city has its own unique characteristics. Under these circumstances, it becomes extremely important to evaluate people's perceptions at the local or regional level. There is lack of knowledge especially in developing regions on evaluating the impacts of parking management measures in changing the behavioral intentions towards the metro-bus service. It is also required to understand the role of pro-social norms and social constraints in understanding the behavioral intentions of commuters towards the metro-bus system. In addition, some of the incentives attributes of the metro-bus were also added in this research. It was hypothesized that the commuter's social constraints and parking restrictions influence their behavioral intentions with some incentives on using the metro-bus over a private car. Social constraints and parking restrictions may have direct effects on personal norms or moral obligations of commuters to use the metro-bus for the reduction of air pollution, traffic congestion, and preservation of natural resources. The metro-bus intentions with incentives have a direct correlation with the personal norms of the commuters. It was also hypothesized that the personal and trip characteristics may have significant correlations with the metro-bus behavioral intentions, the personal norms and commuters' behavioral intentions may vary across different income groups. These entire hypotheses were tested for significance using ANOVA and SEM analyses.

\section{Characteristics of the Study Area}

Lahore is the 2nd biggest city of Pakistan and the capital of the most populace province, Punjab, with an estimated population of more than 11 million and the area of the city is believed to be extended about $1792 \mathrm{~km}^{2}$ [57]. It has many medical, educational, and recreational facilities and industrial zones. It also provides a lot of employment opportunities for a great portion of the population from the surrounding areas. Due to the presence of 
these facilities and industrial zones, many people travel from suburban and rural areas which generate high travel demand. In the densely populated regions, the demand for public transport is more as compared to the outskirt areas. The unprecedented growth in the mobility patterns have taken place in the few years because of the construction of underpasses, flyovers, and, most importantly, because of the introduction of metro-bus and orange line train services in the transport infrastructure of the city. Currently, the public transport system in the city consists of para-transit services, metro-bus system with a length of $28 \mathrm{~km}$ and orange-line metro train route of $27.1 \mathrm{~km}$ length. However, it is pertinent to mention that the conventional public transport system is still dominant in the city because of its easy accessibility, cheaper costs, and better coverage. The capacity of the conventional transport modes ranges from 4-20 passengers which can be transported using these para-transit services. These modes also serve as feeder routes to the metro-bus service. All of the combined public transport modes constitute around $20 \%$ of the total modal share of Lahore city [58]. The share of the private modes in the model share is very high that causes an increase in traffic congestions on the road network.

Metro bus service was started in February 2013 having $28 \mathrm{~km}$ long route with 29 bus stations between Gajumata and Shahadra. This bus route was selected along one of the major arteries of the city. This route connects many important destinations, including commercial areas, business centers, and official buildings. Route map of the metro bus service with station details, typical bus-stop, and articulated bus route are presented in Figure 1 [59]. Around $8 \mathrm{~km}$ section of the route is elevated. The metro-bus route with the help of feeder routes provides spatial coverage to wider area of the city. It passes through some of the main commercial markets and connects them with densely developed residential areas. The high-density developments near some sections of the metro-bus route are also helpful in generating more metro trips as it can be accessed by walking. The park-and-ride facilities are also provided at some of the stations for the bicyclists and motorcyclists. They can securely park their vehicles near stations and take a ride of the metro-bus. The metro-bus uses e-ticketing and smart card methods for the fare collection. Real-time information is also provided to the passengers during their traveling related to the bus stations or stops and estimated time to reach the next station.

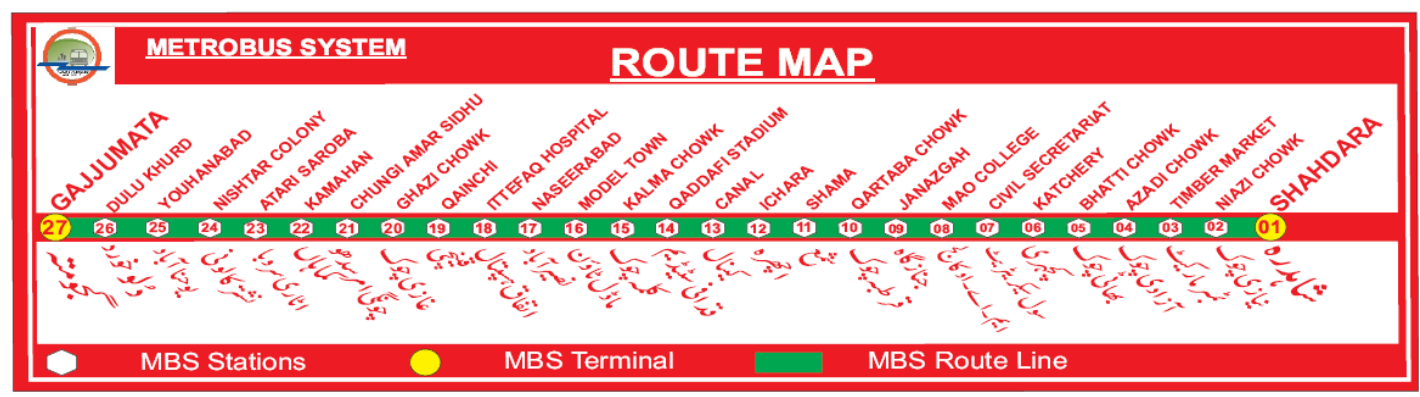

(a)

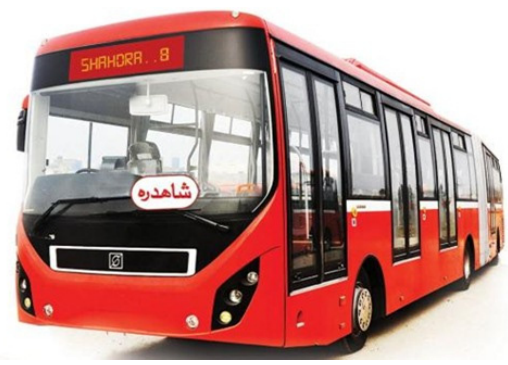

(b)

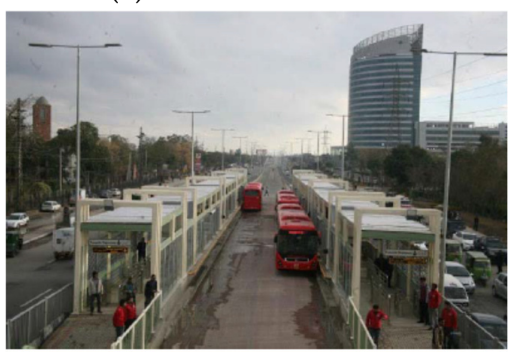

(c)

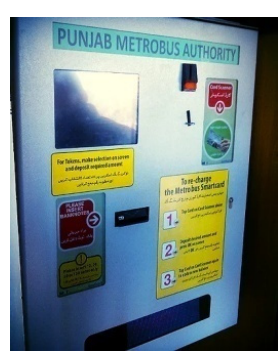

(d)

Figure 1. Metro bus route, a typical articulated bus, and station. (a) Metro-bus route map with station details. (b) A typical articulated bus. (c) A typical at-grade station. (d) A ticket machine. (Source: Punjab Mass-transit Authority. Available online: https://pma.punjab.gov.pk/lmbsrm (accessed on 3 January 2022)). 
The metro-bus service usually operates at varying headways of around 2.25 to $3 \mathrm{~min}$ during the peak-hours and its operation starts at 06:15 a.m. in the morning and ends around 10:00 p.m. at night [59]. The flat fare of 30 PKR is charged for one ride regardless of the origin and destination on the route. A metro-bus guide with video is also available at the website of the Punjab Mass-transit Authority (PMA). This guide includes a video demonstration related to the process of obtaining a ticket and charging smart cards. There are separate compartments inside the bus for the male and female travelers which are separated in order to ensure the security, safety, and maintain the necessary privacy of the female commuters $[3,59,60]$. The stations are equipped with escalators to make convenient access. Various feeder modes are connecting the users to access the metro-bus, such as the conventional bus system, minibus, auto and Qingqi rickshaw and minivans. Some newer feeder routes are also started by the government to facilitate the people who live far from the metro route and want to use this service. Metro bus route can carry almost 112,000 people per day [59].

\section{Methods}

\subsection{Questionnaire Design and Survey}

A questionnaire was designed in this study comprising the traveler's socio-economic demographics (SEDs) and behavioral intentions towards the metro-bus service considering various constraints, metro-bus incentives, and disincentives on the use of private car. The respondent's age, gender, marital status, vehicle ownership, occupation, education, and personal income were asked in the first part of the questionnaire. The second part of the questionnaire consisted of the travel characteristics of the respondents, such as frequent travel mode, trip frequency, travel time, and cost of frequent travel mode, and trip distance of a commuting trip. The third part of the questionnaire consisted of various statements related to commuter's intentions to use metro-bus service considering various situational factors, mobility constraints, incentives, and moral obligations. The main hypothesis of social constrained statements included traveling alone, travelling with friends, and other family members. It was assumed that travelling alone and with others may result in different behavioral intentions towards the public transport as coupling and social constraints or social ties tend to influence the mode choice behavior of the people [49,61]. Economic and other incentives were included in designing the statements to ask the respondents' intentions towards metro-bus. These incentives included reduced travel cost and time with metro-bus service in comparison to a private car. It was assumed that reduced travel time and cost with the metro-bus service may have significant impact on altering user's behavioral intentions. These incentives will serve as pull measures to attract people towards the metro-bus. Additionally, disincentives on the use of a private car were included such as parking restrictions and charges. These disincentive schemes will suffice the purpose as push measures in shifting the people from private car to the public transport modes. Respondent's moral obligations were also asked to use the metro-bus service for the reduction of the traffic congestion, air pollution and to preserve the natural resources.

In this survey, the users who use different modes for their daily commute were also included. The purpose of surveying the users of various modes is to know their intentions with the metro service under various scenarios. A convenience-based random sampling strategy was adopted in the selection of the potential respondents. This survey was conducted alongside the metro-bus route at selected locations where it was possible to find the target population. It was assured that the target respondents should be aware about metro-bus route and should have been either living or working near the metro-bus route and stations. The sample size was determined considering the minimum requirements of sample size for use in the Structural Equation Modeling (SEM) [62-65]. All the respondents were interviewed at their convenience. At the start of the survey, the respondents were instructed regarding the contents and objectives of the survey. A total of 333 usable samples were obtained in this survey. 


\subsection{Analysis Methods}

The collected data were analyzed using the multivariate statistical analysis methods. Initially, the Principal Component Analysis (PCA) was conducted on commuter's perceptions of designed statements related to the metro-bus service behavioral intentions. PCA is an exploratory analysis approach that provides the required factors or components. Cronbach's alpha values were estimated to check the reliability of the collected data and extracted components. The extracted components or factors were combined to construct a structural model using the Structural Equation Modeling (SEM) technique. Many studies have used this multi-variant analysis technique in analyzing the travel behavior patterns [66,67]. A structural model is a combination of several measurement models. The SPSS AMOS software was used to develop the structural models. The AMOS analysis uses a confirmatory approach to construct the structure and test several hypotheses at the same time. This technique also elicits the direct and indirect effects between the variables of a structural model. In this study, it was hypothesized that the commuter's intentions with the metro-bus service under various constraints, mobility restrictions, and incentives influence their moral obligations or personal norms. The structural model was extended by including observed variables concerning the socio-economic and personal features of the travelers. The adequacy of the structural models was examined using a significance level of measurement, structural equations, and comparing indices of the goodness of fit parameters with their permissible or recommended values in the literature. The selected goodness of fit parameters included the ratio of Chi-square to the Degree of Freedom ( $\left.\chi^{2} / \mathrm{DF}\right)$, Goodness of Fit Index (GFI), Adjusted Goodness of Fit Index (AGFI), Comparative Fit Index (CFI), and Root Mean Square Error of Approximation (RMSEA). The recommended value of $\chi^{2} / \mathrm{DF}$ is $2-5, \mathrm{CFI}, \mathrm{GFI}$, and AGFI is more than 0.9, and RMSEA is supposed to be less than $0.08[68,69]$.

\section{Results and Discussion}

\subsection{Descriptive Statistics of Sample}

The descriptive statistics of the respondent's SEDs are shown in Table 1. The share of the male respondents is more than the female respondents. Most of the respondents belong to the age group of 21-30 years. More than $60 \%$ of the respondents own a car and more than $50 \%$ own a motorcycle. Around $45 \%$ of the respondents possess a driving license. Results show that private cars and motorcycles have a major share in the study model split which is consistent with their actual share among the motorized modes in Lahore city [58]. Most of the respondents work in private and civil organizations.

Table 1. SEDs of the respondents.

\begin{tabular}{|c|c|}
\hline Characteristics & Distribution (\%) \\
\hline Gender & Male (67.6), female (32.4) \\
\hline Marital status & Single (65.8), married (34.2) \\
\hline Age (years) & Under $20(4.8), 21-30(72.7), 31-40(12.6), 41-50(8.1)$, above $50(1.8)$ \\
\hline Household size & 3 or less than $3(11.7), 4-5(36.1), 5-6(36.0)$, more than $6(16.2)$ \\
\hline Profession & Student (23), civil employees (42), private employees (28), others (7) \\
\hline Personal income (PKR) & $\begin{array}{c}<15,000(27), 15,000-25,000(12), 26,000-40,000(28), 41,000-60,000(19), \\
\text { more than } 60,000(14)\end{array}$ \\
\hline Frequent travel mode & $\begin{array}{c}\text { Walking/bicycle (13), private car (29), motorcycle (32), public } \\
\text { transport (22), auto-rickshaw / taxi (4) }\end{array}$ \\
\hline Trip frequency & 5-7 days a week (85.6), 3-4 days a week (9.0), 1-2 days a week (5.4) \\
\hline Lives in a joint family & Yes (49.2), No (50.8) \\
\hline Have a driving license & Yes (44.7), No (55.3) \\
\hline Motorcycle ownership & Yes (49.2), No (50.8) \\
\hline Car ownership & Yes (61.3), No (38.7) \\
\hline
\end{tabular}




\subsection{Distribution of Responses on the Metro-Bus Intentions}

The distribution of the respondents' responses on attitudes and intentions towards the metro-bus service is shown in Figure 2. It shows that the commuter's intentions to use the metro-bus service in situational and social constraints are quite low, especially when they are traveling with their family members. It means that they would prefer private modes of transport when going out with the family members. The selected parking restrictions such as a parking fee of Rs. 100 and limited parking spaces near the metro-bus route have shown a significant impact on the commuter's behavioral intentions to use the metro-bus service. It is evident that the implementation of mentioned parking management measures would have significant impact on changing traveler's behavioral intentions. High parking fees and limited parking spaces would discourage the use of private transport and encourage use of the metro-bus service. The incentives of the direct access by the metro-bus to the important destinations, service reliability, and the travel cost and time reduction have important considerations in changing the behavioral intentions of the travelers. It is prevalent that the people may prefer the metro-bus over private car if it provides better access or has better spatial coverage, the travel cost and time are lower than the use of car. The respondents have shown high moral obligations to use the metro-bus service for the community and economic benefits which depict their pro-social behavior. The presence of such pro-social norms is usually helpful in shaping sustainable travel behaviors among the travelers $[5,70,71]$.

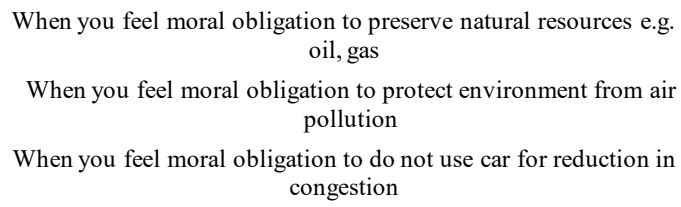

When you feel moral obligation to do not use car for reduction in congestion

When seat is assured in metro-bus with same travel time as car

When metro-bus is more reliable mode than private car

When seat is assured in metro-bus with same travel cost as a car

When travel time by metro-bus is 10 minutes less than a car travel time

When travel cost by metro-bus is half of car

When you can reach many important destinations directly by metro-bus

When entry of car is restricted in metro-bus service area

When the parking fee for car is about $100 \mathrm{PKR}$ at the destination

When parking is very far from your destination place

When parking is limited at the destination place

Travelling with elder family members

Travelling to office/school/university with friends

Travelling to office/school/university with family members

Travelling alone to office/school/university

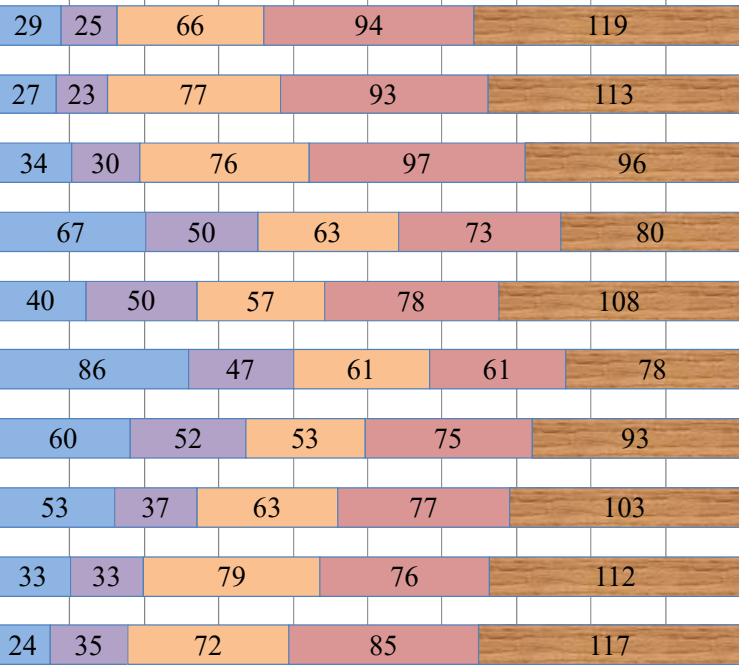

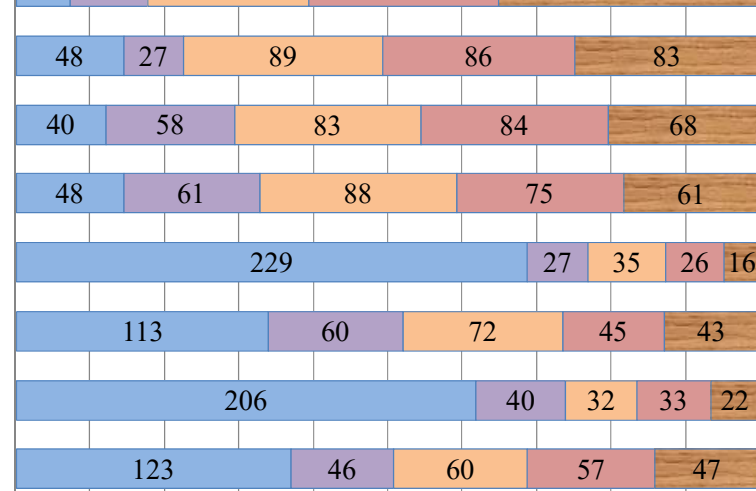

$\begin{array}{lllllllllll}0 \% & 10 \% & 20 \% & 30 \% & 40 \% & 50 \% & 60 \% & 70 \% & 80 \% & 90 \% & 100 \%\end{array}$

$$
\square \text { Never } \quad \square \text { Rarely } \square \text { Sometimes } \quad \square \text { Often } \quad \text { Always }
$$

Figure 2. Frequency distribution of the respondent's intentions towards metro-bus. 


\subsection{Average Responses on the Metro-Bus Intentions across Different Income Groups}

The sample was divided into three categories considering the income group of respondents, i.e., low-income ( $\geq 20,000$ PKR), middle-income (21,000-40,000 PKR), and highincome (more than 40,000 PKR). The sample sizes of low-income, middle-income, and high-income are 112,112, and 109, respectively. Average responses were estimated about the metro-bus behavioral intentions and are presented in Figure 3. The contours in the diagram represent the statement scale from 1 to 5 , where 1 is never and 5 is always. The radar diagram in Figure 3 shows that there is a difference in the perceptions of these income groups. The average responses are almost the same across three groups when they need to travel with their elder family members. It is clear from the figure that the low-income group places high intentions for the metro-bus service considering various social constraints, mobility restrictions, and incentives. The high-income people have shown low intentions towards buses under given circumstances. Their intentions are only more when there are some heavy restrictions on the car use such as when the entry of a car is restricted in the public transport service area.

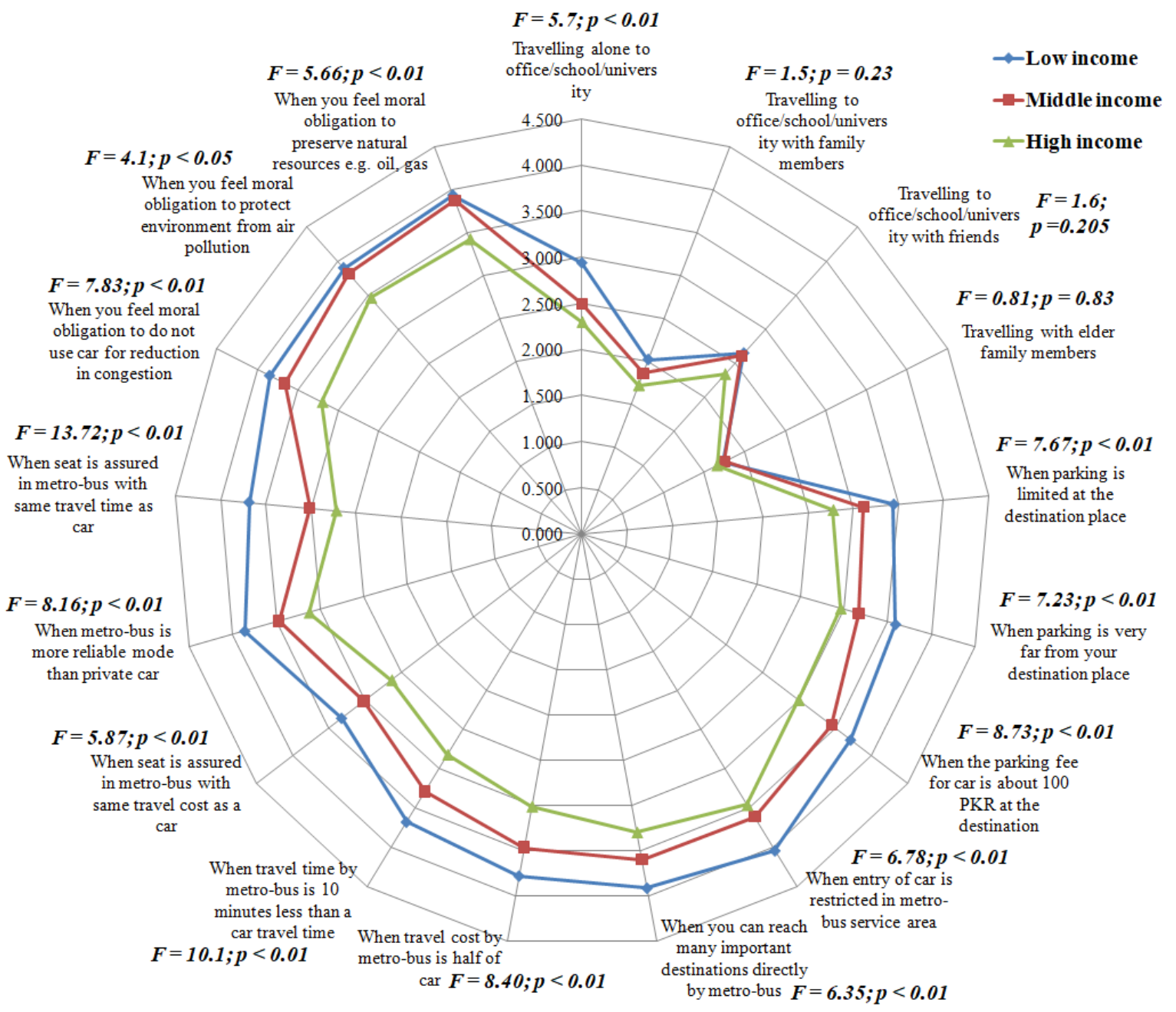

Figure 3. Average responses with ANOVA results for three income groups.

One-way ANOVA analysis was conducted on the behavioral intentions across the three groups to determine the statistical significance of their differences in responses. The $F$-statistics and significance values are shown in Figure 3. This analysis showed that the responses of low-, middle-, and high-income respondents are not statistically different when they are traveling with their family members and friends, whereas the responses are statistically significantly different when they are traveling alone. Similarly, the responses 
for other behavioral intentions towards the metro-bus service are statistically significant and different across the three income groups of the respondents. These results depict that the behavioral intentions of low-income, middle-income, and high-income respondents differ significantly when certain mobility incentives and restrictions are imposed.

\subsection{Exploratory Factor Analysis}

The Principal Component Analysis technique was employed for the extraction of explanatory factor analysis on the commuter's perceptions. The component rotation was done using the varimax rotation method. A factor loadings value of 0.5 was used for the extraction purposes. This component analysis resulted in four components for an eigenvalue greater than 1.0 as shown in Table 2. The estimates of KMO and Bartlett's tests show that the sample size is adequate for an explanatory factor analysis as the value of $\mathrm{KMO}$ is more than 0.7 and the test is highly significant [72,73]. These components were named based on the nature of the questions asked in the questionnaire. These components are (1) Metro-Bus Incentives (MBI), (2) Social Constraints (SC), (3) Personal Norms (PN), and (4) Parking Restrictions (PR). The \% of variance explained by all these four factors is more than $60 \%$ of the total variance which is within an acceptable range. Additionally, the values of the estimated Cronbach's alpha confirm the acceptable level of reliability because the value is more than 0.7 which validates the internal consistency among respondents in the evaluation of the indicators or observed variables [72,73]. The first factors of MBI included indicators concerning hypothetical metro-bus incentives over private car such as more reliable and cheap service, less travel time with metro-bus service, direct access to many important destinations by metro-bus, and seat assurance in the bus service. This factor shows that the commuters placed a high score on the reliability, cost and travel time saving, and direct access attributes. The second factor of SC shows that the situational and social constraints have a significant influence on the commuter's intentions to use the metro-bus service. Commuters would like to use their personalized vehicles when they are traveling with their family members. The results of the PN depict that the travelers have a high moral obligation to use the metro-bus service for the reduction of traffic congestions, air pollution, and the preservation of the natural resources. These pro-social norms would help to promote the use of the public transportation modes such as metro-bus service. The last factor of PR shows that the selected parking restrictions such as restricted and far parking and parking fee have a significant influence on changing the commuter's intentions towards the metro-bus service.

\subsection{Structural Equation Modeling of Metro-Bus Intentions}

The SEM model was developed using PCA technique in order to understand the relationships of different latent variables. It was hypothesized that the situational and social constraints and parking restrictions may have a significant direct influence on the metro-bus intentions (MBI) under various incentives and personal norms (PN). A direct structural relationship was assumed between $\mathrm{MBI}$ and PN. It was also hypothesized that the passenger's SEDs and trip characteristics may impact their norms. Therefore, the observed variables of the SED sand trip characteristics are clearly defined and incorporated in the model. However, these variables are coded for the convenience of analysis as binary variables (i.e., 1, 0). It is pertinent to mention that the variables which are statistically significant are only presented in Figure 4. The defined variables incorporated are profession ( 1 if the profession belongs to the group of private employees, otherwise is 0 ; 1 if the profession belongs to the group of civil employees, otherwise is 0 ), marital status (1 if respondents are married, otherwise is 0 ), motorcycle ownership (yes: 1, no: 0 ), and have a driving license (yes: 1 , no: 0 ). The variable of the trip distance was included in $\mathrm{km}$. 
Table 2. Results of rotated principal component analysis (PCA).

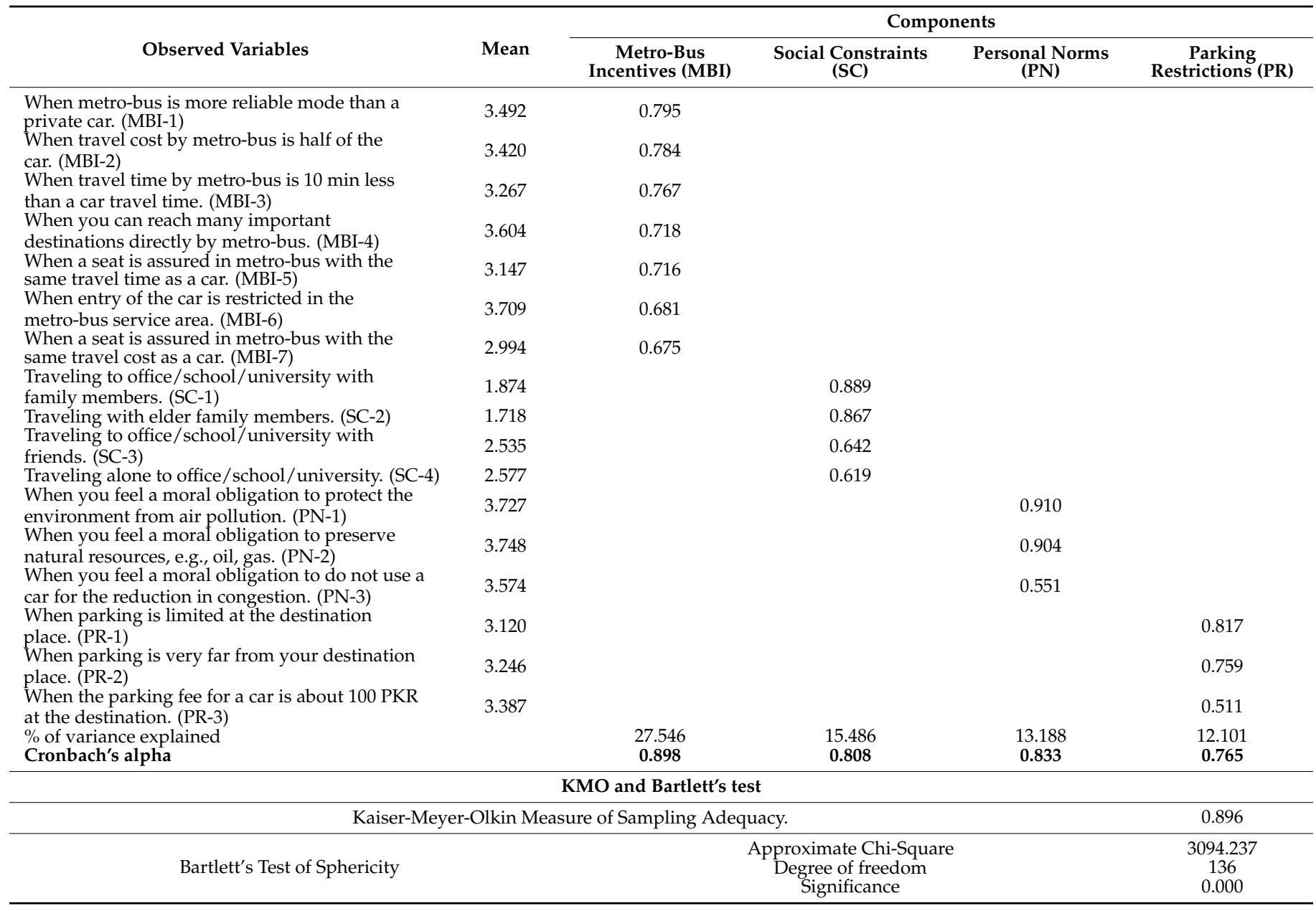

The significance of all of the measurement equations was checked at a $1 \%$ level of significance and confirmed their association with their corresponding latent variables (factors) as shown in Figure 4. PR and SC have a positive and significant association with each other. The structural coefficient of SC with MBI is insignificant. The structural relationship of PR with MBI is positive and significant at a $1 \%$ level of significance. This positive coefficient depicts that the respondent's behavioral intentions under parking restrictions have a positive association with the metro-bus incentives in comparison to the car. It is argued that parking restrictions in combination with metro-bus incentives would be handy in promoting the use of metro-bus service among the existing and potential commuters. The SC and PR explain almost $59 \%$ of the variance in the MBI.

The structural relationship of SC with PN is insignificant. The PR has a positive and significant structural construct with PN. It shows that the respondents who have positive intentions to use the metro-bus with parking restrictions also feel a moral obligation to reduce the use of private cars, protect the environment from air pollution, and preserve the natural resources. The structural coefficient of MBI with $\mathrm{PN}$ is positive and significant at a $1 \%$ level of significance. This relationship depicts that the respondent's positive intentions with the metro-bus incentives over a private car have a significant influence in developing the pro-social norms among the commuters. These positive norms can be handy in the long run to reduce the use of private vehicles and promote the use of mass transit modes $[5,13,71]$. 


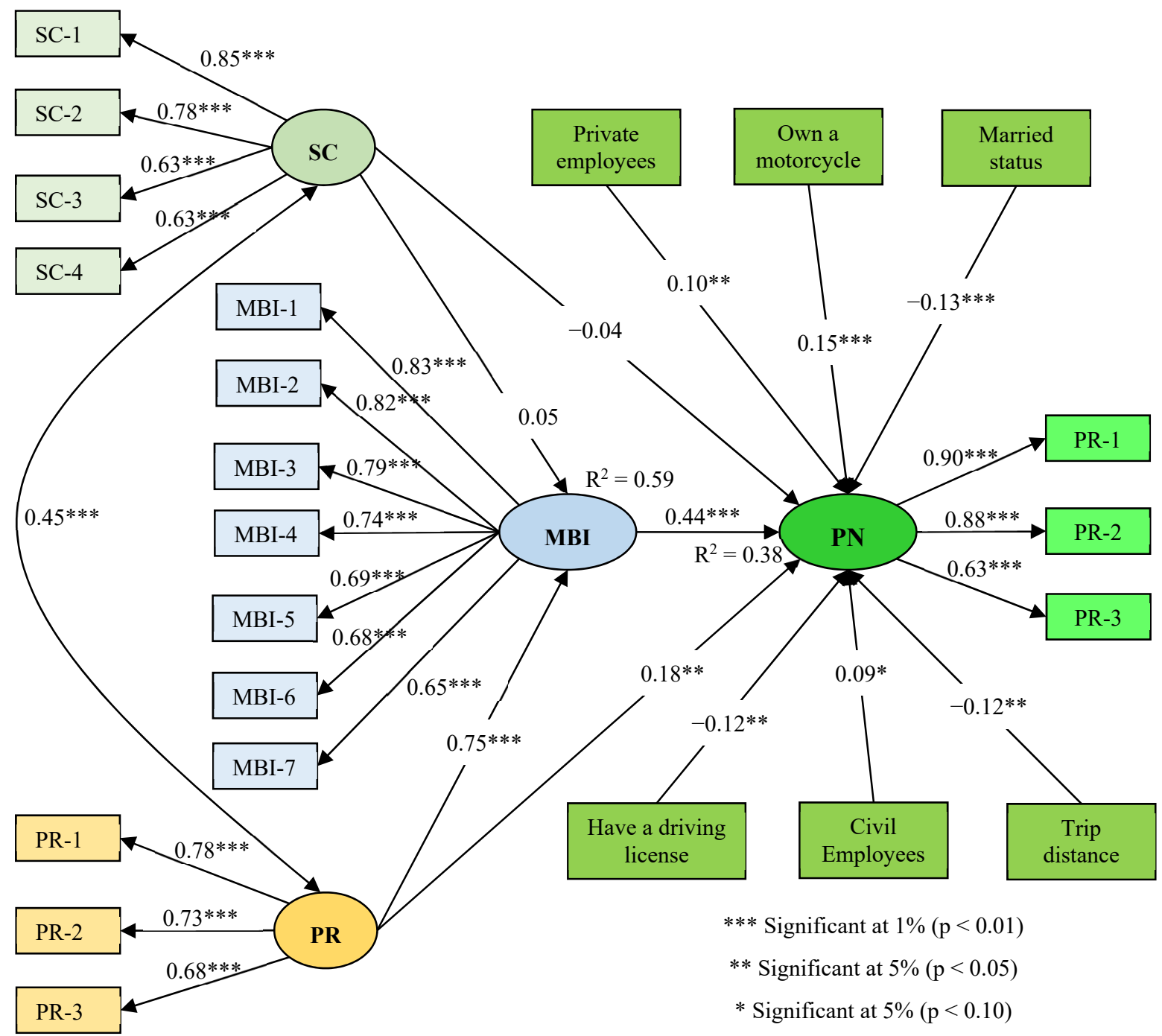

$\mathrm{CMIN} / \mathrm{DF}=3.548, \mathrm{GFI}=0.816, \mathrm{AGFI}=0.774, \mathrm{CFI}=0.826, \mathrm{RMSEA}=0.088$.

Figure 4. A structure of commuter's intentions towards metro-bus service.

The commuter's profession such as civil and private employees has a positive and significant association with the latent variable of PN. It shows that the employees feel a moral obligation and possess pro-social travel behavior. These pro-social behavioral intentions among employees can be useful in promoting the use of the public transport modes. The respondents who are married and possess a driving license formed negative structural coefficients with PN. These coefficients show that the commuters with a driving license and family members have low intentions to reduce the use of a private car for the reduction of traffic congestion, air pollution, and preservation of the natural resources. Other studies have also shown that the traveler's characteristics, such as profession, marital status, and vehicle ownership, have a significant influence on the behavioral intentions $[18,45,74]$. It is found that an increase in the trip distance has a negative impact on the moral obligations of the people as the structural coefficient is negative. The respondents who own a motorcycle have a positive association with the formation of moral obligations among them. The MBI, SC, and PR and significant personal and travel characteristics explain almost $38 \%$ of the variance in the PN. The values of all the threshold indices are within the acceptable range which confirmed the validity of the proposed SEM model in explaining the commuter's behavioral intentions towards metro-bus. 


\subsection{Structural Models of Low-, Medium-, and High-Income Groups}

The SEM analysis was performed to draw a comparison between low-income, middleincome, and high-income groups. The sample sizes for low, middle, and high-income people are 112, 112, and 109, respectively. The standardized estimates of the structural equations and measurement equations are presented in Table 3 and Figure 5, respectively. All the measurement equations of the three groups were positive and significant at a $1 \%$ level of significance. Some differences have existed in the standardized estimates or regression weights among the three groups as shown in Table 3.

Table 3. Standardized estimates of measurement equations of the three income groups.

\begin{tabular}{cccccc}
\hline \multicolumn{2}{c}{ Measurement Equation } & Low-Income & Middle-Income & High-Income \\
\hline PN-3 & $<-$ & PN & 0.736 & 0.459 & 0.646 \\
PN-2 & $<-$ & PN & 0.904 & 0.854 & 0.882 \\
PN-1 & $<-$ & PN & 0.837 & 0.952 & 0.921 \\
SC-2 & $<-$ & SC & 0.689 & 0.866 & 0.796 \\
SC-4 & $<-$ & SC & 0.617 & 0.572 & 0.715 \\
SC-1 & $<-$ & SC & 0.797 & 0.874 & 0.859 \\
SC-3 & $<-$ & SC & 0.635 & 0.517 & 0.748 \\
PR-3 & $<-$ & PR & 0.703 & 0.495 & 0.749 \\
PR-1 & $<-$ & PR & 0.763 & 0.734 & 0.831 \\
PR-2 & $<-$ & PR & 0.641 & 0.798 & 0.697 \\
MBI-4 & $<-$ & MBI & 0.741 & 0.706 & 0.726 \\
MBI-2 & $<-$ & MBI & 0.846 & 0.847 & 0.764 \\
MBI-7 & $<-$ & MBI & 0.628 & 0.671 & 0.713 \\
MBI-3 & $<-$ & MBI & 0.725 & 0.812 & 0.798 \\
MBI-1 & $<-$ & MBI & 0.763 & 0.897 & 0.789 \\
MBI-6 & $<-$ & MBI & 0.644 & 0.647 & 0.717 \\
MBI-5 & $<-$ & MBI & 0.703 & 0.651 & 0.644 \\
\hline
\end{tabular}

Note: <- shows the measurement equation or relationship between observed variable and latent variable PN: personal norm, SC: social constraints, PR: parking restrictions, MBI: Metro-bus incentives.

The structural estimates in Figure 5a of the low-income group show that the PR has positive and significant coefficients with MBI and PN which depict that the behavioral intentions of low-income people under parking restrictions have a positive association with their moral obligations and intentions towards the metro-bus service with given incentives. SC and PR have a positive association with each other. In middle-income models in Figure 5b, the PR has only a significant relationship with MBI whereas the structural coefficient with PN was insignificant. Figure $5 \mathrm{c}$ shows that the PR has a significant structural construct both with MBI and PN. The structural estimate of private employees with PN is the only significant relationship in the low-income model. In the middle-income model, the variables of marital status, motorcycle ownership, and trip distance have significant structural relationships with the PN. In the high-income model, all the defined variables of the personal and travel characteristics (same as the base model in Figure 4) have significant structural relationships with the PN. The impacts of motorcycle ownership, marital status, trip distance, profession, and driving license variables on PN are the same as of the base model in Figure 4. The income level and profession of commuters and trip distance have a significant influence on traveler's behavioral intentions [75-77].

The commuter's behavioral intentions with the metro-bus incentives have a positive construct with their moral obligations in all three models. It predicts that the pro-social norms of the commuters are helpful to reduce the traffic congestion and air pollution in the city and preserve the natural resources. The overall comparison of the measurement and structural equations with their significance level and indices of the goodness-of-fit parameters show that the structural model of high-income groups has a better representation of the base model in predicting the behavioral intentions and personal norms of the commuters. 
$\mathrm{CMIN} / \mathrm{DF}=1.597, \mathrm{GFI}=0.841, \mathrm{AGFI}=0.789$,

$\mathrm{CFI}=0.913, \mathrm{RMSEA}=0.073$

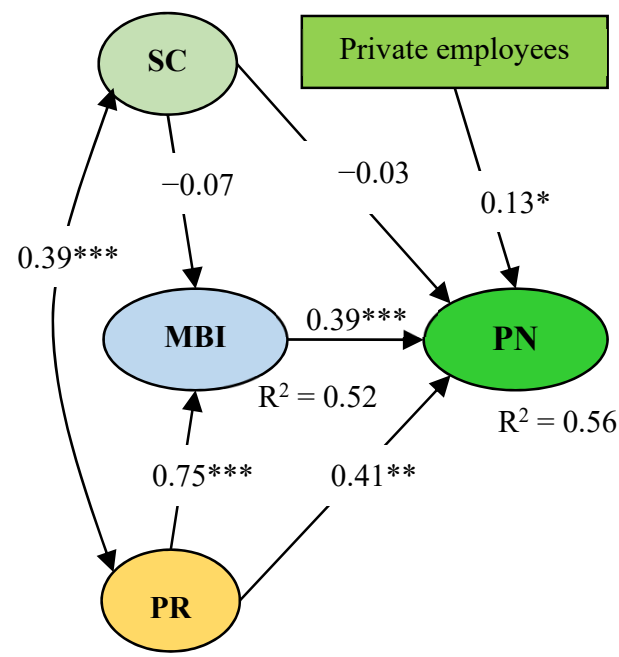

(a) Structural equations of low-income group

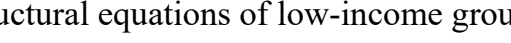

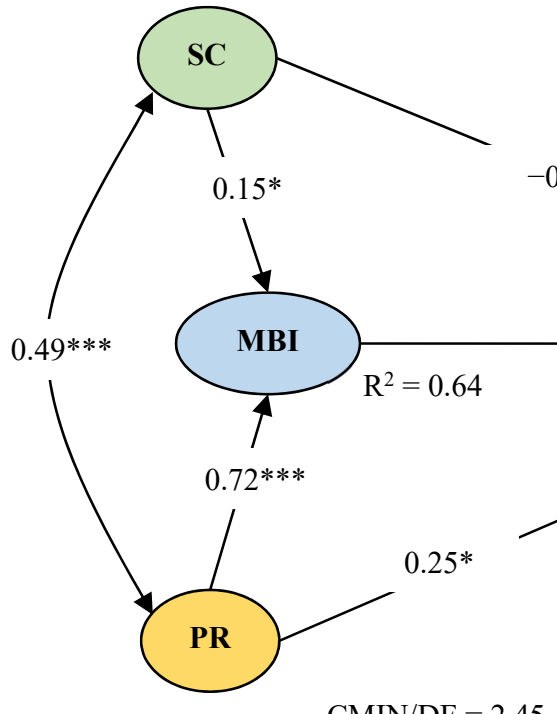

$\mathrm{CMIN} / \mathrm{DF}=2.45, \mathrm{GFI}=0.709, \mathrm{AGFI}=0.642, \mathrm{C}$

(c) Structural equations of high-income

\footnotetext{
*** Significant at $1 \%(\mathrm{p}<0.01), * *$ Significant at $5 \%(\mathrm{p}<0.05),{ }^{*}$ Significant at $5 \%(\mathrm{p}<0.10)$
}

Figure 5. Standardized estimates of three income groups' structural models.

\subsection{Policy Implications}

The ANOVA and SEM results depict that the differences exist among three economic groups of the samples in their behavioral intentions towards the metro-bus service considering travelling alone, moral obligations, parking restrictions, and metro-bus incentives. The respondent's behavioral intentions remain the same across the three groups when they are travelling with family members which are on the lower side. It implies that traveling alone and traveling with family members is a significant personal constraint which determines the mode choice intentions of the local people. This fact can be attributed to the security and privacy concerns of the people because sometimes people do not feel comfortable on the public transport when they are travelling with their family members especially females $[54,55,78]$. There is a need to provide some service benefits such as assuring security 
and privacy of the female passengers and economic incentive schemes for the families to enhance the use and ridership of the metro-bus service.

Metro-bus incentives, such as the reduced travel time and cost, better access, spatial coverage, and better comfort through assured seat, would be useful in attracting the potential users and changing the behavioral intentions. These incentives are usually helpful in improving the transit ridership and travel comfort of the passengers [38]. These incentives schemes are required to be implemented along with the disincentives on use of private car such as parking management programs. This research implies that through the intervention of increased parking fees, commuters showed a positive inclination towards the use of the metro bus system. Therefore, the traffic management authorities (such as Traffic Engineering and Planning Agency, Lahore Development Authority) must consider soliciting a parking management system to discourage the use of the private car through the implementation of parking fee, especially alongside the metro-bus route. It is believed that the excess of parking spaces encourage travelers to use private transport; therefore, limiting parking spaces near the metro route would help to discourage the use of private car and promote the use of metro-bus $[79,80]$. An integrated approach is required in implementing the incentive and disincentive Traffic Demand Management (TDM) measures to improve their effectiveness in reducing the traffic congestion and enhancing the use of the transit system.

The findings of this research study imply that most of the respondents showed a positive moral obligation towards the environment protection and preserving the natural resources. Therefore, a good consideration of air quality improvement and policies pertinent to the climate change impact can be recognized with the promotion of better public transit systems in the city. The personal norms and social concerns usually help in shaping the sustainable travel choices among people $[5,49,70]$. Improved transit facilities with incentive schemes and parking restrictions on the use of private car would help in developing the transit-oriented attitudes among the travelers and moral obligations to use environmentally friendly transport modes. The policymakers should think of ways for providing safe and comfortable public transport using eco-vehicles which contribute less emission in the eco-system. Better environmental quality can be mandated by removing the old conventional bus fleet and replacing it with a better public transport system such as the metro-bus system. The cognitive variables play an important role in defining the sustainable travel behavior and traveler's awareness about the metro-bus benefits can be helpful in shaping the positive perceptions and behavioral intentions of the commuters [81]. In order to avoid an increase in the use of private transport in the coming months, attention must also be paid to the changes in the modal choice and frequency experienced during the recent COVID-19 pandemic due to the restrictions imposed by the governments. In addition, pervasive fear of infection and feeling of stress aboard public transport in the pandemic is also a concern [82,83]. Therefore, it is also required to create awareness among general public about the benefits and incentives associated with the use of metro-bus service such as awareness campaigns which should focus on improving the perceptions towards the use of public transport.

\section{Conclusions}

The government policies to develop and improve the public transport facilities usually help in the model shift and reduce the traffic congestion. Additionally, the economic disincentives on use of private car and parking restrictions can help reduce the use of private transport and shift people towards public transport. However, this model shift is influenced by several factors, including individual's personal and social constraints, service quality of the transit facilities and road infrastructure characteristics. This study attempted to identify the commuter's behavioral intentions to use the metro-bus service under the influence of various constraints, moral obligations, incentives, and restrictions. The required data were obtained with the help of a questionnaire survey and analyzed using ANOVA and SEM methods. Survey results revealed that the behavioral intentions of the commuters 
differ with the social and personal constraints in traveling. The commuters traveling with their family members would prefer to use the private car and such intentions do not differ across low-, middle-, and high-income people. However, significant differences exist between three income groups about their behavioral intentions considering mobility incentives and specific parking restrictions. The moral obligations of three income groups also vary across three groups for the reduction in the traffic congestion, air pollution and conservation of the natural resources.

Parking restrictions, such as limited, far parking and high parking fees, have a significant influence on the commuter's behavioral intentions towards the metro-bus system. Social constraints in traveling, the metro-bus incentives over a private car, and parking restrictions are significant determinants of commuter's moral obligations for reduction in the traffic congestion, pollution and protecting the natural resources. Additionally, profession, motorcycle ownership, marital status, trip distance, and possession of a driving license are significant predictors of personal norms to use the metro-bus service. These influencing factors implicate that parking management measures can be deployed to change the behavioral intentions and promote the use of transit modes. Commuter's awareness and norms can also be handy in developing positive attitudes towards the metro-bus and other transit modes. The situational constraints result in negative behavioral intentions towards bus service. Public transport incentive programs for combined traveling of the family members and elderly people may help in enhancing the use of the transit service. The public transport incentives over private vehicles are essential to make a significant model shift from the private modes to public transit modes. The public transport behavioral intentions are derived from a small sample which may not reflect the perceptions of the whole population and city. In addition, this study included only a few social constraints, incentives schemes, and parking restrictions in the evaluation. Future studies may focus on including various service quality dimensions of the available transit modes, traveler's attitudes, privacy, and personality characteristics in assessing the behavioral intentions and moral obligations.

Author Contributions: Conceptualization, M.A.J., N.A. and T.C.; methodology, M.A.J. and N.A.; data collection, N.A. and M.A.J.; data analysis, M.A.J. and N.A.; writing-original draft preparation, M.A.J., N.A., T.C., K.C. and G.T.; writing-review and editing, M.A.J., N.A., T.C., K.C. and G.T.; funding, T.C., K.C. and G.T. All authors have read and agreed to the published version of the manuscript.

Funding: This research received no external funding.

Institutional Review Board Statement: Ethical review and approval were waived for this study, due to this study being a non-interventional study that did not involve biological human experiments and patient data. In addition, this study was completely voluntary and non-coercive, and responses remain anonymous.

Informed Consent Statement: The respondents were informed that their responses would remain anonymous and would be used for research purposes only.

Data Availability Statement: The data can be made available from the corresponding author upon reasonable request.

Acknowledgments: This work was supported by the Thammasat Research Unit in Infrastructure Inspection and Monitoring, Repair and Strengthening (IIMRS), Thammasat School of Engineering, Faculty of Engineering, Thammasat University Rangsit, Klong Luang Pathumthani, Thailand. Authors also extend their appreciation to the respondents for their time and efforts to make this study possible.

Conflicts of Interest: The authors declare no conflict of interest. 


\section{References}

1. Wright, L.; Fjellstrom, K. Module 3a. In Sustainable Transport: A Sourcebook for Developing Cities; Institute for Transportation and Development Policy: New York, NY, USA, 2003.

2. Susilo, Y.O.; Joewono, T.B.; Santosa, W. An Exploration of Public Transport Users' Attitudes and Preferences towards Various Policies in Indonesia: Some Preliminary Results. J. East. Asia Soc. Transp. Stud. 2010, 8, 1230-1244.

3. Javid, M.A.; Abdullah, S.; Hashmi, A.I.; Akbar, M.U.; Ghazanfar-Ullah, M. Passengers' attitudes and preference towards metro-bus service in Lahore. J. Urban Environ. Eng. 2018, 12, 201-209. [CrossRef]

4. Javid, M.A.; Hussain, S.; Anwaar, M.F. Passenger's Perceptions on Prospects of Qingqi Paratransit Public Transport Service in Lahore. Iran. J. Sci. Technol. Trans. Civ. Eng. 2020, 44, 185-195. [CrossRef]

5. Javid, M.A.; Okamura, T.; Nakamura, F.; Tanaka, S.; Wang, R. Factors Influencing the Acceptability of Travel Demand Management Measures in Lahore: Application of Behavioral Theories. Asian Transp. Stud. 2015, 3, 447-466. [CrossRef]

6. De Groot, J.I.M.; Steg, L.; Dicke, M. Transportation trends from a moral perspective: Value orientations, norms and reducing car use. In New Transportation Research Progress; Gustavsson, F.N., Ed.; Nova Science Publishers: New York, NY, USA, 2008 ; pp. 67-91. ISBN 9781604560329.

7. Abrahamse, W.; Steg, L.; Gifford, R.; Vlek, C. Factors influencing car use for commuting and the intention to reduce it: A question of self-interest or morality? Transp. Res. Part F Traffic Psychol. Behav. 2009, 12, 317-324. [CrossRef]

8. Steg, L. Car use: Lust and must. Instrumental, symbolic and affective motives for car use. Transp. Res. Part A Policy Pract. 2005, 39, 147-162. [CrossRef]

9. Belwal, R. People's perception of public transport services in Oman. J. Teknol. Sci. Eng. 2013, 65, 9-16. [CrossRef]

10. Ben-Dor, G.; Ben-Elia, E.; Benenson, I. Assessing the Impacts of Dedicated Bus Lanes on Urban Traffic Congestion and Modal Split with an Agent-Based Model. Procedia Comput. Sci. 2018, 130, 824-829. [CrossRef]

11. Nguyen-Phuoc, D.Q.; Young, W.; Currie, G.; De Gruyter, C. Traffic congestion relief associated with public transport: State-of-theart. Public Transp. 2020, 12, 455-481. [CrossRef]

12. De Oña, J.; de Oña, R.; Eboli, L.; Forciniti, C.; Mazzulla, G. Transit passengers' behavioural intentions: The influence of service quality and customer satisfaction. Transp. A Transp. Sci. 2016, 12, 385-412. [CrossRef]

13. Tao, S.; Corcoran, J.; Mateo-Babiano, I. Modelling loyalty and behavioural change intentions of busway passengers: A case study of Brisbane, Australia. IATSS Res. 2017, 41, 113-122. [CrossRef]

14. Ferguson, E. Transportation demand management planning, development, and implementation. J. Am. Plan. Assoc. 1990, 56, 442-456. [CrossRef]

15. Do, M.; Jung, H. The Socio-Economic Benefits of Sharing Economy: Colleague-Based Carpooling Service in Korea. J. Open Innov. Technol. Mark. Complex. 2018, 4, 40. [CrossRef]

16. Javid, M.A. Travel Demand Management Policies Prospects for Lahore: Rating and Classification. Int. J. Innov. Res. Eng. Manag. 2016, 3, 409-413.

17. Javid, M.A.; Okamura, T.; Nakamura, F.; Tanaka, S.; Wang, R. People's behavioral intentions towards public transport in Lahore: Role of situational constraints, mobility restrictions and incentives. KSCE J. Civ. Eng. 2016, 20, 401-410. [CrossRef]

18. Nordfjærn, T.; Egset, K.S.; Mehdizadeh, M. “Winter is coming”: Psychological and situational factors affecting transportation mode use among university students. Transp. Policy 2019, 81, 45-53. [CrossRef]

19. Beirão, G.; Cabral, J.A.S. Understanding attitudes towards public transport and private car: A qualitative study. Transp. Policy 2007, 14, 478-489. [CrossRef]

20. Zuo, Y.; Fu, X.; Liu, Z.; Huang, D. Short-term forecasts on individual accessibility in bus system based on neural network model. J. Transp. Geogr. 2021, 93, 103075. [CrossRef]

21. Lei, D.; Chen, X.; Cheng, L.; Zhang, L.; Ukkusuri, S.V.; Witlox, F. Inferring temporal motifs for travel pattern analysis using large scale smart card data. Transp. Res. Part C Emerg. Technol. 2020, 120, 102810. [CrossRef]

22. Liu, Y.; Lyu, C.; Liu, X.; Liu, Z. Automatic Feature Engineering for Bus Passenger Flow Prediction Based on Modular Convolutional Neural Network. IEEE Trans. Intell. Transp. Syst. 2021, 22, 2349-2358. [CrossRef]

23. Belwal, R.; Belwal, S. Public Transportation Services in Oman: A Study of Public Perceptions. J. Public Transp. 2010, $13,1-21$. [CrossRef]

24. Zolnik, E.J.; Malik, A.; Irvin-Erickson, Y. Who benefits from bus rapid transit? Evidence from the Metro Bus System (MBS) in Lahore. J. Transp. Geogr. 2018, 71, 139-149. [CrossRef]

25. Delmelle, E.C.; Casas, I. Evaluating the spatial equity of bus rapid transit-based accessibility patterns in a developing country: The case of Cali, Colombia. Transp. Policy 2012, 20, 36-46. [CrossRef]

26. Bus Rapid Transit System [BRT] and Road Safety-Arrive Alive. Available online: https://www.arrivealive.mobi/bus-rapidtransit-system-brt-and-road-safety (accessed on 7 September 2021).

27. Shah, S.A.R.; Shahzad, M.; Ahmad, N.; Zamad, A.; Hussan, S.; Aslam, M.A.; Khan, A.R.; Asif, M.A.; Shahzadi, G.; Waseem, M. Performance Evaluation of Bus Rapid Transit System: A Comparative Analysis of Alternative Approaches for Energy Efficient Eco-Friendly Public Transport System. Energies 2020, 13, 1377. [CrossRef]

28. Hinebaugh, D. Characteristics of Bus Rapid Transit for Decision-Making. Sci. Am. 2004, 301, 412.

29. Stutsman, J.M. Bus Rapid Transit or Light Rail Transit-How to Decide?: Los Angeles Case Study. Transp. Res. Rec. 2002, 1793, 55-61. [CrossRef] 
30. Kepaptsoglou, K.; Milioti, C.; Spyropoulou, D.; Haider, F.; Karlaftis, A.G. Comparing traveler preferences for BRT and LRT systems in developing countries: Evidence from Multan, Pakistan. J. Traffic Transp. Eng. (English Ed.) 2020, 7, 384-393. [CrossRef]

31. Liu, X.; Gao, L.; Ni, A.; Ye, N. Understanding better the influential factors of commuters' multi-day travel behavior: Evidence from Shanghai, China. Sustainability 2020, 12, 376. [CrossRef]

32. Hirsch, L.R.; David Jordan, J.; Hickey, R.L.; Cravo, V. Effects of Fare Incentives on New York City Transit Ridership. Transp. Res. Rec. J. Transp. Res. Board 2000, 1735, 147-157. [CrossRef]

33. Chen, W.; Cao, C.; Fang, X.; Kang, Z. Expanding the theory of planned behaviour to reveal urban residents' pro-environment travel behaviour. Atmosphere 2019, 10, 467. [CrossRef]

34. Collins, P.A.; MacFarlane, R. Evaluating the determinants of switching to public transit in an automobile-oriented mid-sized Canadian city: A longitudinal analysis. Transp. Res. Part A Policy Pract. 2018, 118, 682-695. [CrossRef]

35. Soltanpour, A.; Mesbah, M.; Habibian, M. Customer satisfaction in urban rail: A study on transferability of structural equation models. Public Transp. 2020, 12, 123-146. [CrossRef]

36. Soza-Parra, J.; Raveau, S.; Muñoz, J.C.; Cats, O. The underlying effect of public transport reliability on users' satisfaction. Transp. Res. Part A Policy Pract. 2019, 126, 83-93. [CrossRef]

37. Habib, K.M.N.; Kattan, L.; Islam, M.T. Model of personal attitudes towards transit service quality. J. Adv. Transp. 2011, 45, 271-285. [CrossRef]

38. Li, L.; Cao, M.; Bai, Y.; Song, Z. Analysis of Public Transportation Competitiveness Based on Potential Passenger Travel Intentions: Case Study in Shanghai, China. Transp. Res. Rec. 2019, 2673, 823-832. [CrossRef]

39. Jen, W.; Tu, R.; Lu, T. Managing passenger behavioral intention: An integrated framework for service quality, satisfaction, perceived value, and switching barriers. Transportation 2011, 38, 321-342. [CrossRef]

40. Chowdhury, S.; Zhai, K.; Khan, A. The Effects of Access and Accessibility on Public Transport Users' Attitudes. J. Public Transp. 2016, 19, 97-113. [CrossRef]

41. Redman, L.; Friman, M.; Gärling, T.; Hartig, T. Quality attributes of public transport that attract car users: A research review. Transp. Policy 2013, 25, 119-127. [CrossRef]

42. Mittal, S.; Dai, H.; Fujimori, S.; Hanaoka, T.; Zhang, R. Key factors influencing the global passenger transport dynamics using the AIM/transport model. Transp. Res. Part D Transp. Environ. 2017, 55, 373-388. [CrossRef]

43. Minser, J.; Webb, V. Quantifying the benefits: Application of customer loyalty modeling in public transportation context. Transp. Res. Rec. 2010, 111-120. [CrossRef]

44. Heath, Y.; Gifford, R. Extending the theory of planned behavior: Predicting the use of public transportation. J. Appl. Soc. Psychol. 2002, 32, 2154-2189. [CrossRef]

45. Collins, C.M.; Chambers, S.M. Psychological and Situational Influences on Commuter-Transport-Mode Choice. Environ. Behav. 2005, 37, 640-661. [CrossRef]

46. Sánchez-Atondo, A.; García, L.; Calderón-Ramírez, J.; Gutiérrez-Moreno, J.M.; Mungaray-Moctezuma, A. Understanding public transport ridership in developing countries to promote sustainable urban mobility: A case study of Mexicali, Mexico. Sustainability 2020, 12, 3266. [CrossRef]

47. Javid, M.A.; Okamura, T.; Nakamura, F.; Tanaka, S.; Wang, R. Public Perceptions to Travel Demand Management Measures in Lahore, Pakistan: Analysis and Implications. Proc. Pakistan Acad. Sci. 2014, 51, 17-29.

48. Hassan, A.; Shahin, M.M.; Morsy, M. Area traffic capacity in centeral areas-Alexandria city center as a case study. Alexandria Eng. J. 2011, 50, 367-380. [CrossRef]

49. Kaewkluengklom, R.; Satiennam, W.; Jaensirisak, S.; Satiennam, T. Influence of psychological factors on mode choice behaviour: Case study of BRT in Khon Kaen City, Thailand. Transp. Res. Procedia 2017, 25, 5072-5082. [CrossRef]

50. Nadeem, M.; Azam, M.; Asim, M.; Al-Rashid, M.A.; Puan, O.C.; Campisi, T. Does Bus Rapid Transit System (BRTS) Meet the Citizens' Mobility Needs? Evaluating Performance for the Case of Multan, Pakistan. Sustainability 2021, 13, 7314. [CrossRef]

51. Ambak, K.; Kumar Kasvar, K.; Daniel, B.D.; Prasetijo, J.; Raqib, A.; Ghani, A. Behavioral Intention to Use Public Transport Based on Theory of Planned Behavior. In Proceedings of the the 3rd International Conference on Civil and Environmental Engineering for Sustainability, Melaka, Malaysia, 1-2 December 2015; pp. 1-7.

52. Nkurunziza, A. Analysing Commuters' Attitudes towards the Proposed Bus Rapid Transit System in Dar es Salaam, Tanzania: Using Stated Choice and Spatial Analysis. Master's Thesis, International Institute for Geo-Information Science and Earth Observation, Enschede, The Netherlands, 2008.

53. Borhan, M.N.; Syamsunur, D.; Akhir, N.M.; Razuhanafi, M.; Yazid, M.; Ismail, A.; Rahmat, R.A. Predicting the Use of Public Transportation: A Case Study from Putrajaya, Malaysia. Sci. World J. 2014, 2014, 784145. [CrossRef]

54. Adeel, M.; Yeh, A.G.O.; Zhang, F. Gender inequality in mobility and mode choice in Pakistan. Transportation 2017, 44, 1519-1534. [CrossRef]

55. Malik, B.Z.; ur Rehman, Z.; Khan, A.H.; Akram, W. Women's mobility via bus rapid transit: Experiential patterns and challenges in Lahore. J. Transp. Heal. 2020, 17, 100834. [CrossRef]

56. Chaudhary, M.L. Commuters' Perceptions on Service Quality of Bus Rapid Transit Systems: Evidence from the Cities of Ahmedabad, Surat and Rajkot in India. Eur. Transp./Trasp. Eur. 2020, 79, 1-16. [CrossRef]

57. Punjab Bureau of Statistics Punjab Development Statistics. Available online: http://www.bos.gop.pk/developmentstat (accessed on 30 June 2020). 
58. Japan International Cooperation Agency (JICA). The Project for Lahore Urban Transport Master Plan in the Islamic Republic of Pakistan; JICA: Tokyo, Japan, 2012.

59. Government of Punjab Lahore Metrobus System (Route Map) | Punjab Masstransit Authority. Available online: https://pma. punjab.gov.pk/lmbsrm (accessed on 25 December 2020).

60. Javid, M.A.; Okamura, T.; Nakamura, F. Public Satisfaction with Service Quality of Daewoo Urban Bus Service in Lahore. J. East. Asia Soc. Transp. Stud. 2015, 11, 1097-1108.

61. Phithakkitnukoon, S.; Sukhvibul, T.; Demissie, M.; Smoreda, Z.; Natwichai, J.; Bento, C. Inferring social influence in transport mode choice using mobile phone data. EPJ Data Sci. 2017, 6, 11. [CrossRef]

62. Wolf, E.J.; Harrington, K.M.; Clark, S.L.; Miller, M.W. Sample Size Requirements for Structural Equation Models: An Evaluation of Power, Bias, and Solution Propriety. Educ. Psychol. Meas. 2013, 73, 913-934. [CrossRef] [PubMed]

63. Nicolaou, A.I.; Masoner, M.M. Sample size requirements in structural equation models under standard conditions. Int. J. Account. Inf. Syst. 2013, 14, 256-274. [CrossRef]

64. Guadagnoli, E.; Velicer, W.F. Relation of Sample Size to the Stability of Component Patterns. Psychol. Bull. 1988, 103, 265-275. [CrossRef] [PubMed]

65. Boomsma, A.; Hoogland, J.J. The Robustness of LISREL Modeling Revisited. In Structural Equation Models: Present and Future. A Festschrift in Honor of Karl Jöreskog; Scientific Software International: Lincolnwood, IL, USA, 2001; pp. 139-168.

66. De Oña, J.; De Oña, R.; Eboli, L.; Mazzulla, G. Perceived service quality in bus transit service: A structural equation approach. Transp. Policy 2013, 29, 219-226. [CrossRef]

67. Javid, M.A.; Al-Hashmi, W.Y.; Al-Shaqsi, A.S. Exploring the Student's Perceptions on Safety Aspects of the University of Nizwa Bus Service in Oman. Iran. J. Sci. Technol. Trans. Civ. Eng. 2020, 45, 227-239. [CrossRef]

68. Hu, L.T.; Bentler, P.M. Cutoff criteria for fit indexes in covariance structure analysis: Conventional criteria versus new alternatives. Struct. Equ. Model. 1999, 6, 1-55. [CrossRef]

69. Bentler, P.M.; Chou, C.P. Practical Issues in Structural Modeling. Sociol. Methods Res. 1987, 16, 78-117. [CrossRef]

70. Bamberg, S.; Hunecke, M.; Blöbaum, A. Social context, personal norms and the use of public transportation: Two field studies. J. Environ. Psychol. 2007, 27, 190-203. [CrossRef]

71. Mehdizadeh, M.; Nordfjaern, T.; Mamdoohi, A.R. Environmental norms and sustainable transport mode choice on children's school travels: The norm-activation theory. Int. J. Sustain. Transp. 2019, 14, 137-149. [CrossRef]

72. Brown, T.A. Confirmatory Factor Analysis for Applied Research; The Guilford Press: New York, NY, USA, 2006; ISBN 1-59385-274-6 (Paperback); 1-59385-275-4 (Hardcover); 978-1-59385-274-0 (Paperback); 978-1-59385-275-7 (Hardcover).

73. Samuels, P. Advice on Exploratory Factor Analysis; Technical Report; Birmingham City University: Burmingham, UK, 2017 ; pp. 1-7. [CrossRef]

74. Trinh, T.A.; Linh Le, T.P. Investigating Proenvironmental Behavior: The Case of Commuting Mode Choice. IOP Conf. Ser. Earth Environ. Sci. 2018, 143, 12067. [CrossRef]

75. Nguyen, H.T.A.; Chikaraishi, M.; Fujiwara, A.; Zhang, J. Mediation effects of income on travel mode choice: Analysis of short-distance trips based on path analysis with multiple discrete outcomes. Transp. Res. Rec. 2017, 2664, 23-30. [CrossRef]

76. Hajinasab, B.; Davidsson, P.; Persson, J.A.; Holmgren, J. Towards an Agent-Based Model of Passenger Transportation; Lecture Notes in Computer Science (including subseries Lecture Notes in Artificial Intelligence and Lecture Notes in Bioinformatics); Springer: Berlin/Heidelberg, Germany, 2016; Volume 9568, pp. 132-145.

77. Amoh-Gyimah, R.; Aidoo, E.N. Mode of transport to work by government employees in the Kumasi metropolis, Ghana. J. Transp. Geogr. 2013, 31, 35-43. [CrossRef]

78. Zulfiqar, F. Public Transportation System and Female Mobility in Pakistan-PIDE Blog. Available online: https://pide.org.pk/ blog/public-transportation-system-and-female-mobility-in-pakistan/ (accessed on 8 September 2021).

79. Christiansen, P.; Engebretsen, Ø.; Fearnley, N.; Usterud Hanssen, J. Parking facilities and the built environment: Impacts on travel behaviour. Transp. Res. Part A Policy Pract. 2017, 95, 198-206. [CrossRef]

80. Hess, D.B. The Effects of Free Parking on Commuter Mode Choice: Evidence from Travel Diary Data. Transp. Res. Rec. J. Transp. Res. Board 2001, 1753, 35-42. [CrossRef]

81. Sener, I.N.; Lee, K.; Durand, C.P.; Oluyomi, A.O.; Kohl, H.W., III. Intention to use light-rail transit in Houston, Texas, United States: Findings from the Travel-Related Activity in Neighborhoods study. Int. J. Sustain. Transp. 2020, 14, 944-955. [CrossRef]

82. Basbas, S.; Georgiadis, G.; Campisi, T.; Tesoriere, G. Factors Influencing Public Transport Demand in Sicily During COVID-19 Era: A Study of Commuters' Travel and Mode Choice Behaviors; Lecture Notes in Computer Science (Including Subseries Lecture Notes in Artificial Intelligence and Lecture Notes in Bioinformatics); Springer: Berlin/Heidelberg, Germany, 2021; Volume 12954, pp. 339-353. [CrossRef]

83. Basbas, S.; Campisi, T.; Georgiadis, G.; Al-Rashid, M.A.; Tesoriere, G. COVID-19 and public transport demand trends in Sicily: Analyzing external factors and governmental recommendations. Eur. Transp. Trasp. Eur. 2021, 83, 15. [CrossRef] 